ISSN 2179-6750

\title{
O ensino-aprendizagem da libras para agentes comunitários de saúde: qualificando o atendimento em saúde para surdos de Viçosa-MG
}

\author{
Thayane Fraga de Paula, Ana Luisa Borba Gediel, Mylene Mayara Santos Dias
}

\begin{abstract}
Resumo
O presente estudo é fruto do Projeto de extensão intitulado "LIBRAS em Interface com as Unidades de Saúde: Práticas pedagógicas voltadas aos profissionais da saúde que prestam atendimento às pessoas Surdas de Viçosa, MG”. Este, foi desenvolvido durante o ano de 2013, em parceria entre a UFV e a Secretaria Municipal de Saúde de Viçosa, com financiamento via programa FUNARBEX. Capacitar os agentes comunitários de saúde em relação a Língua Brasileira de Sinais (LIBRAS). Tal meta surgiu a partir da demanda dos profissionais de saúde, atuantes nas Estratégias de Saúde da Família - ESFs de Viçosa - MG, em aprender a LIBRAS, e, consequentemente, proporcionar um atendimento de saúde com maior qualidade aos Surdos atendidos por estas unidades. Os cursos de formação e capacitação ocorreram de acordo com a base teórico-metodológica do Curso de Extensão em LIBRAS- CELIB, da UFV, em duas etapas: O curso básico I, em que foram trabalhados os temas vocabulário e palavras do cotidiano; e o básico II, para o desenvolvimento da formação inicial de frases e a respeito dos temas de saúde e o atendimento de saúde em LIBRAS. Como forma de refletir acerca das aulas e a aquisição de um conhecimento significativo de LIBRAS, durante todo o curso, foram realizadas avaliações qualitativas, por meio de ditados, questões acerca dos temas discutidos em sala e elaboração de atividades em LIBRAS para apresentar aos colegas. O método utilizado foi de caráter participativo, visando uma perspectiva dialógica, no sentido de proporcionar a troca de experiências de maneira reflexiva. Desse modo, além do ensino e aprendizagem da LIBRAS, os (as) cursistas puderam refletir sobre suas práticas de saúde, favorecendo a criação de novos parâmetros de ação junto a esse grupo minoritário. Tendo em vista as avaliações, o projeto apresentou resultados satisfatórios, uma vez que todo (as) os(as) cursistas atingiram notas acima da média de $75 \%$ no básico I e acima da média de $80 \%$ no Básico 2. Ademais, os participantes demonstraram satisfação pelo curso e interesse em continuidade. O curso de formação trouxe benefícios aos profissionais que participaram de tal iniciativa, proporcionado conhecimento significativo acerca da LIBRAS e promovendo um atendimento de saúde mais inclusivo, integral e humanizado aos Surdos de Viçosa-MG.
\end{abstract}

Descritores: LIBRAS; Surdos; Educação em Saúde 